Rapid Reviews COVID-19•

\title{
Reviews of: "The Unequal Burden of the Covid-19 Pandemic: Racial/Ethnic Disparities in US Cause- Specific Mortality"
}

Ladan Golestaneh $^{1}$, Samrachana Adhikari ${ }^{2}$

${ }^{1}$ Albert Einstein College of Medicine, ${ }^{2}$ NYU Langone Health

Published on: Oct 21, 2021

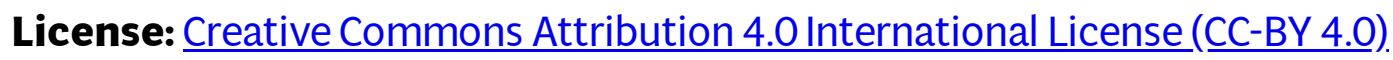


To read the original manuscript, click the link above.

Summary of Reviews: This preprint contributes new evidence that Black and Hispanic populations share the greatest burden of COVID-19 pandemic. Reviewers found main claims to be strong and potentially informative. There are important implications for policy and practice.

\section{Reviewer 1 (Ladan G...) |}

Reviewer 2 (Samrachana A...) |

$$
\begin{aligned}
& \text { RR:C19 Strength of Evidence Scale Key. } \\
& \text { प्रमप = Misleading }
\end{aligned}
$$

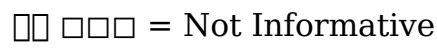

$$
\begin{aligned}
& \text { प्रा पि = Potentially Informative }
\end{aligned}
$$

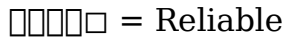

$$
\begin{aligned}
& \text { प्राप्र = Strong }
\end{aligned}
$$

To read the reviews, click the links below. 